\title{
Angola: (Re-)Imaginar o Nascimento de uma Nação no Cinema Militante
}

\author{
MARIA DO CARMO PIÇARRA \\ Universidade do Minho \\ University of Reading
}

\begin{abstract}
The present article examines the use of cinema as an instrument of national liberation in colonial Angola. After contextualizing the use of cinema by independence movements in Portugal's former colonies, I question first whether the activities of cineclubes in Angola contributed to the development of militant films. I then explore whether the fact that Angola's independence struggle had early on been the subject of filmed international reportage was a determining factor in the use of film as an instrument of struggle, even before the publication of Fernando Solanas e Octavio Getino's "Towards a Third Cinema" (1969). Finally, I focus on the use of cinema by the MPLA, analyzing Sarah Maldoror's cinematic adaptation of José Luandino Vieira's narratives of militance and colonial incarceration.
\end{abstract}

Keywords: Africa, colonial cinema, independence, Sarah Maldoror, MPLA

São escassos os estudos sobre como as lutas de libertação foram representadas nas imagens em movimento. Este artigo procura contribuir para o estudo sobre como, durante o Estado Novo português, em Angola, os filmes foram usados como uma arma de propaganda política ou postos ao serviço da militância pela causa da libertação do colonialismo. 
No âmbito de uma genealogia do cinema militante em Angola, proponho que o surgimento de um cinema de causas foi integrado no movimento cineclubista, e que o impacto provocado pelas imagens da luta pela independência de Angola, mostrada em reportagens internacionais filmadas, foi também determinante para uma consciência, por parte dos líderes dos movimentos independentistas, da importância do cinema como arma de propaganda, ainda antes da publicação de "Towards a Third Cinema" dos realizadores argentinos Fernando Solanas e Octavio Getino (1969). O manifesto, em que Solanas e Getino mapearam o cinema de Hollywood, o cinema de autor e o cinema consagrado à descolonização, propondo a organização da produção cinematográfica em primeiro, segundo e terceiro cinema, terá sido inspirador para o Movimento para a Libertação de Angola (MPLA) pôr o cinema ao serviço da sua causa. ${ }^{1}$ Particularizo, pois, o uso do cinema pelo MPLA e analiso, num estudo de caso central para a história do cinema feito em África, os filmes de Sarah Maldoror, que adaptam cinematograficamente os contos de José Luandino Vieira (1935- ) sobre militância política e encarceramento colonial. ${ }^{2}$

Como é que as representações coloniais dispostas pelo Estado Novo (19331974) foram sendo questionadas pelos movimentos de libertação em Angola? Como Claire Andrade-Watkins fez notar, as colónias portuguesas partilharam "the legacy of a harsh and impoverished colonial reign" (135), e não possuíam infraestruturas de produção cinematográfica ou técnicos com formação. Devido a isso, o desenvolvimento de uma produção cinematográfica não foi fácil durante as lutas de libertação ou posteriormente às independências das ex-colónias portuguesas. Cabo Verde e S. Tomé e Príncipe nunca foram capazes de criar cinematografias nacionais, não obstante uma importante atividade cineclubista registada em Cabo Verde nos anos 60 (Andrade-Watkins).

A falta de infraestruturas e técnicos não obstou a que alguns líderes dos movimentos de libertação desenvolvessem ideias sobre como o filme podia ser

\footnotetext{
${ }^{1}$ Num desenvolvimento posterior das suas ideias, Solanas e Getino definem cinema militante como feito por colectivos implicados em organizações políticas revolucionárias. Os filmes não se definem como radicais quanto à experimentação com linguagem fílmica; é o seu valor de uso ou instrumentalização em função de uma agenda política revolucionária que lhe determinam o significado.

2 José Mateus Vieira da Graça, nascido em Lisboa, muda-se para Angola durante a infância. O seu nome artístico é Luandino Vieira, numa homenagem, óbvia, a Luanda, onde foi preso e condenado a 14 anos de prisão pela sua militância política e participação na luta pela independência de Angola antes de ser transferido para o Campo do Tarrafal.
} 
usado como ferramenta educativa e forma de documentar e disseminar informação sobre as suas lutas. Após a realização do pioneiro Lala quema (1966), pelo francês Mário Marret, e quando Nô pintcha (1970) já estava a ser feito por Tobias Engels, René Lefort e Gilbert Igel, Amílcar Cabral (1924-1973), líder do Partido Africano para a Independência da Guiné e Cabo Verde (PAIGC), mandou quatro jovens - Flora Gomes (1949-), Sana na N'Hada (1950- ), Josefina Crato (?-2005) and José Bolama Cobumba (1941-1985)—estudar no Instituto Cubano del Arte e Industria Cinematográficos (ICAIC) entre 1967 e 1972 (César; Piçarra e Castro; Cunha e Laranjeiro). O projeto Luta ca caba inda tornou acessível o que sobreviveu desta fase do cinema militante guineense. Com a ajuda de Flora Gomes e Sana na N' Hada - Crato e Cobumba já morreram - Filipa César (1975- ) tem assegurado a preservação e digitalização do material de arquivo.

Quanto a Moçambique, foi a Frente de Libertação de Moçambique (FRELIMO) a tomar consciência da necessidade de propagandear a sua ação para contrariar a propaganda do Estado Novo e passou a usar o cinema quer para afirmar o compromisso em defender os direitos do povo quer com a construção de uma nova sociedade. Não dispondo de realizadores entre as suas fileiras, convidou equipas de cinema estrangeiras solidárias com a luta do movimento. Em 1967, o realizador da Ex-Jugoslávia Dragutin Popovic (1932-2005) realizou Venceremos, documentando a vida quotidiana nas zonas libertadas. A britânica Margaret Dickinson (1943- ) filmou depois Behind the Lines (1971), considerado um dos filmes mais emblemáticos sobre a luta da FRELIMO contra o colonialismo (Gray). Entretanto, televisões e organizações internacionais enviaram equipas de cinema para entrevistar Eduardo Mondlane (1920- ) e Samora Machel (1933-1986), e registar os esforços da FRELIMO para garantir serviços de saúde, ensino e treino militar. O sueco Lennart Malmer (1941- ), que já filmara na Guiné, dirigiu Na nossa terra as balas começam a florir (1973), título inspirado num poema de Jorge Rebelo (1940- ).

Quanto a Angola, após a independência, contou com o apoio do ICAIC para a realização de filmes emblemáticos do nascimento do cinema em Angola, sendo determinante a colaboração de Santiago Álvarez, mas também do coletivo francês Unicité, ligado ao Partido Comunista Francês, o qual, a convite de Luandino Vieira, diretor da Televisão Popular de Angola (1975-78) e do Departamento de Orientação Revolucionária do MPLA (1975-79) antes de passar a dirigir o Instituto Angolano de Cinema (1979-84), assegurou a formação 
técnica de muitos dos futuros realizadores angolanos (Piçarra; Gray). Também vários países de Leste, e sobretudo a Jugoslávia, apoiante do MPLA durante a luta armada, asseguraram a realização de filmes sobre a independência do país. ${ }^{3}$

\section{Cineclubismo e cinema de causas}

Ainda antes dos filmes terem sido usados, em Angola, como uma arma pelos movimentos independentistas, já um cinema de causas, militante, ensaiara um contributo para a criação de um cinema angolano. Será abusivo afirmar que uma das causas do movimento cineclubista surgido em Angola foi a de, através da educação para o cinema e pelo cinema, criar esse cinema?

Paulo Cunha sustenta que este foi muito mais do que um movimento cinéfilo, tendo desempenhado, durante o Estado Novo, "um importante papel de resistência cultural e mesmo de oposição política à ditadura vigente" (43). O autor vai mais longe e propõe que a evolução deste movimento ajuda a compreender as mudanças "socioculturais e político-ideológicas de Portugal no Pós-Segunda Guerra Mundial” (43). ${ }^{4}$

Em Angola, os membros do movimento cineclubista, que se desenvolve na década de cinquenta com forte engajamento social e político, têm uma consciência identitária angolana que se quer exprimir. Manuel Faria sustenta em 1964, na revista Diálogo (dirigida pelo Cine Clube do Huambo, fundado em 1956 e o primeiro de Angola), que "não havia suficiente cultura (angolana) da parte dos indivíduos, honestos" que tentaram criar um cinema angolano. ${ }^{5}$ Faria faz o diagnóstico (14):

A ignorância de todos aqueles que vieram fazer cinema a Angola trouxe, talvez involuntária e inocentemente, o péssimo estado em que se está [...] quer fugindo para o filme de propaganda, quer para um tema exótico filmado em écran grande e colorido, com o obscurecimento total da realidade, mentindo ao público [...].

\footnotetext{
${ }^{3}$ Para mais informação sobre como os movimentos de libertação usaram o cinema como arma, consultar Piçarra e Castro.

${ }^{4}$ Para mais informação sobre o desenvolvimento do movimento-cineclubista português consultar Piçarra e António.

${ }^{5}$ Manuel Faria desapareceu precocemente. Foi irmão de António Faria, realizador de Índia.
} 
Faria afirma o futuro do cinema angolano não será o de um cinema que "mostre animais. Um cinema que não mostre caçadores; nem canibalismos nem selvajarias. Nem mostre o negro para fazer rir. Nem como bom rapaz estereotipado. Nem cinema paternalista. Nem cinema de turistas" (15). O autor defende a existência de um cinema de intervenção e por isso questiona: "[...] que interesse tem um cinema que não foca problemas, meios, e que não é cinema social diretamente ligado à "multidão de gentes" (15).

Também na Diálogo, no artigo "Cinema Experimental Angolano," Artur M. S. Silva tenta responder à questão sobre que "estrutura social" deve este enquadrar:

Não se podendo esquecer as relações económicas é preciso mostrar a minoria que retém os meios de produção e por outro lado o operariado suburbano e o campesinato que se encontra limitado à venda da sua força de trabalho. Acontece, porém, que estes últimos não tendo ao seu alcance a técnica e a instrução encontram-se afastados dos meios de fazer cinema. Isso compete então a uma determinada massa intelectual que embora viva nos quadros do grupo privilegiado adere e participa na problemática do trabalhador africano. (13)

Refere as tentativas do Cine Clube de dinamizar a realização de um cinema social, realista, através de uma série de filmes em $8 \mathrm{~mm}$ "que procuram penetrar no mundo suburbano de Nova Lisboa." Assume, no entanto, serem obras de "reduzido interesse que têm por principal mérito construir experiências que irão revelando um caminho a seguir" (Silva 13). ${ }^{6}$

O certo é que experiências como esta ou aquelas postas em prática por outros cineclubes-Benguela, Lobito, Moçâmedes, Luanda, Huíla-Sá da Bandeira e Uíge - foram fundamentais para promover um cinema de causas, para alimentar a cinefilia em Angola, para viabilizar a formação - em fotografia, sobretudode muitos cinéfilos e fomentar o desenvolvimento do cinema de amadores. Festivais de cinema amador apareceram em várias cidades angolanas,

\footnotetext{
${ }^{6}$ Esses filmes não estão nos arquivos. Ter-se-ão perdido ou pertencem a coleções privadas. $\mathrm{O}$ aparecimento de filmes feitos no âmbito do movimento cineclubista ao serviço da causa do cinema angolano será um contributo inestimável para traçar a genealogia, em sentido foucaultiano, deste.
} 
acompanhando "a geografia e a cronologia do movimento cineclubista angolano, mantendo uma relação direta e próxima com os próprios cineclubes ou os seus dirigentes e dinamizadores" (Cunha 59).

\section{A luta anticolonial mostrada pelas reportagens-filme internacionais}

Robert Young (1924- ) e Robert McCormick (1911-1985) realizaram Angola: Journey to a War (1961) para exibição no programa White Paper, da National Broadcasting Company (NBC). Primeiro e último documentário mostrado pela NBC sobre a luta armada nas então colónias portuguesas, foi determinante para um melhor conhecimento internacional da luta a travar-se em Angola (Piçarra, "O cinema" 17).

Enquanto McCormick e o operador Louis Hepp voam para Luanda, a convite do Estado Novo, para fazerem uma cobertura orientada pela bitola do regime, Young e o operador Charles Dorkins viajam para o Congo, por onde, com o apoio da União das Populações de Angola (UPA), ex-Frente Nacional de Libertação de Angola (FNLA), de Holden Roberto, entram clandestinamente em Angola (Ramos). Percorrem centenas de quilómetros no mato. Serão os primeiros a fazêlo mas outros, como a jornalista italiana Augusta Conchiglia e o companheiro desta, Stefano de Stefani, seguirão os seus passos. Se McCormick e Hepp mostram a prosperidade e paz luandina, Young e Dorkins filmam, nas fazendas do Norte de Angola, os cadáveres que os massacres da UPA deixaram para trás. ${ }^{7}$ A propaganda portuguesa também fixou estas imagens de violência e não hesitou em usá-las sobrepondo-lhe sons, e de modo a potenciar-lhes os efeitos, em Angola na guerra e no progresso (1970), do ex-oficial da Força Aérea Quirino Simões (1931- ) (Piçarra, "O cinema"). Ao longo do percurso, porém, são também filmadas as marcas do napalm lançado pela Força Aérea portuguesa. Young e Dorkins dão a ver e a ouvir ao mundo, pela primeira vez, as razões dos revoltosos, paralelamente à exposição do ponto de vista dos colonos.

Por outro lado, o comentário off propõe leituras novas às imagens de que a propaganda portuguesa se vale e com que visa projetar no mundo a suposta multirracialidade existente. Dados referidos: menos de um por cento da população africana de Angola tem cidadania e o analfabetismo é elevadíssimo.

\footnotetext{
${ }^{7}$ Para mais informação, consultar Ramos; Piçarra e Castro.
} 
Trabalho contratado é um eufemismo para designar trabalho forçado. Mostra-se a destruição provocada pela revolta dos trabalhadores contratados numa plantação de café onde jazem colonos portugueses. A câmara revela a destruição de Buela, uma aldeia onde só restam ruínas das 150 casas antes existentes. $\mathrm{Na}$ ardósia da sala de aulas está inscrito: "15 de março de 1961: independência de Angola.” É o último sinal de insurreição registado na aldeia após a retaliação pelas tropas portuguesas, para vingar a morte do administrador colonial e da sua mulher.

O documentário despertou a atenção de outros repórteres internacionais para a luta pela independência em Angola. O jornalista suíço Pierre-Pascal Rossi (1943- ) foi um dos que decidiu reportar o drama aí vivido. Em julho de 1968, uma equipa da televisão suíça, composta por Rossi, pelo operador de câmara Henri Rossier e pelo realizador Charles Chenou, entra, de novo clandestinamente, no território, guiada pelo Exército de Libertação Nacional de Angola (ELNA), o braço armado do Governo Revolucionário Angolano no Exílio (GRAE), criado em Léopoldeville (Kinshasa) pouco depois da formação da Frente Nacional de Libertação de Angola (FNLA). ${ }^{8}$ Permanecem sete semanas com os guerrilheiros, registando o seu quotidiano e o dos refugiados civis vivendo no mato sobre a sua proteção.

Contactos com a televisão suíça e com Pierre-Pascal Rossi foram infrutíferos quanto ao apuramento do paradeiro deste filme. No entanto, em 1969, foi editado, em França, pela Julliard, um livro homónimo, Pour une guerre oubliée-avec les guerrilleros de l'Angola (Para uma guerra esquecida: com os guerrilheiros de Angola) da autoria de Rossi, que inclui fotografias, além da referência a prisioneiros de guerra portugueses, os quais surgem identificados e fotografados.

Pouco antes de Rossi, em Abril de 1968, uma equipa italiana entrara em Angola mas com os guerrilheiros do MPLA. Depois de ter visto Loin du Vietnam (Longe do Vietname, 1967), Augusta Conchiglia (1948- ) queria ir, com o realizador da RAI Stefano de Stefani (1929- ), filmar a guerra no Norte do Vietname. Joyce Lussu (1912-1998), uma intelectual italiana que, em 1963, traduzira os poemas de Agostinho Neto (1922-1979), sugeriu que fossem antes a Angola filmar a luta pela independência, desconhecida da opinião pública

\footnotetext{
${ }^{8}$ O secretário geral desse governo era Jonas Savimbi (1934-2002), que posteriormente criou a União Nacional para a Independência Total de Angola (UNITA). Nem o MPLA nem a Frente de Libertação para o Enclave de Cabinda (FLEC) quiseram participar no GRAE.
} 
italiana. Quando Neto passou por Itália, dois meses depois, Lussu marcou um encontro entre ele, Conchiglia e de Stefani. A dupla propôs a Neto realizar um filme sobre a guerra no Leste de Angola (a ideia inicial, de filmar em Cabinda, foi afastada por causa da maior dificuldade em fazê-lo), o que o intelectual angolano aceitou após alertá-los para os perigos e dificuldades físicas do empreendimento.

Conchiglia relata que, antes da "aventura angolana," que se prolongou de abril a final de setembro, tinha alguma experiência como fotógrafa de cena em peças de teatro e publicara reportagens na imprensa mas nunca filmara ("Re: Filmes sobre"). Para tal, fez um curso rápido e aprendeu a usar um gravador profissional Nagra. Após a saída de Roma, em janeiro de 1968, Conchiglia e de Stefani fizeram reportagens no Egipto e posteriormente na Zâmbia, para caucionar o "projeto angolano" (a RAI não podia tutelar uma "entrada ilegal" em Angola) antes de chegar à Tanzânia onde se encontrava então parte da direção do MPLA. Aí foram feitos os planos de viagem e definido o que poderiam Conchiglia e de Stefani fazer além de lhes ter sido feito um enquadramento da situação política e social. Após a passagem pela Tanzânia seguiu-se a ida para a Zâmbia de onde, de Lusaka, partiram em direção à fronteira, numa camioneta do MPLA. ${ }^{9}$

A entrada em Angola, por Cassamba, foi fácil, sem encontros com a polícia ou o exército portugueses, pois os "postos de fronteira por onde passámos eram controlados pelo MPLA." As dificuldades na travessia de rios e estradas de terra batida cedo foram esquecidas quando passaram a deslocar-se exclusivamente a pé no interior do território. "A realidade era duríssima: grandes distâncias, pouca comida e muito cansaço." Em termos de "contactos humanos" foi, porém, uma grande experiência "quer com os guerrilheiros quer com os elementos do povo que pudemos entrevistar ou com quem convivemos. Nem todos os comandantes eram loquazes ou amáveis, mas encontrei figuras formidáveis em termos de sensibilidade pessoal, dedicação e até cultura" ("Re: Filmes sobre").

\footnotetext{
${ }^{9}$ Questionada sobre se tinha havido contactos com outros movimentos de libertação, Conchiglia explicou que, na altura, não sabiam da existência da UNITA e que "a FNLA, com as suas ligações à Mobutu e aos americanos, não nos interessava" ("Re; Filmes sobre").
} 


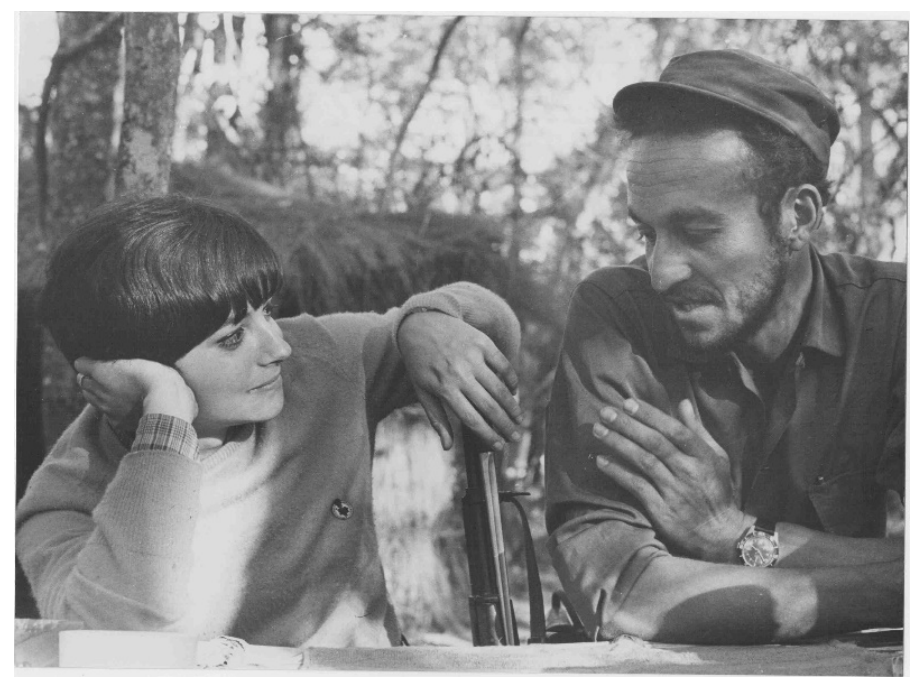

Fig. 1. Augusta Conchiglia e Iko Carreira, na Frente Leste de Angola, em 1968. (C) Augusta Conchiglia

Cazombo, na região do Moxico, foi o primeiro ponto de paragem. Queriam filmar a linha de comboio, já pouco utilizada devido à ação da guerrilha. Num perfil de Conchiglia assinado por José Luís Mendonça e publicado na revista angolana Austral, Conchiglia conta: "Não chegámos até lá porque, entretanto, fomos chamados até à zona $\mathrm{A}$. Acho que andámos cerca de 300 quilómetros. Chegámos em abril à zona A, na base Mandume II, algumas semanas depois da morte do comandante Hoji ya Henda" (103). Posteriormente, Conchiglia e de Stefani foram conduzidos até Lumbale-Lucusse, no sul, para fazerem a cobertura de uma conferência regional do MPLA, a primeira na "terceira região político-militar," em que esteve presente Agostinho Neto. Acabaram por filmar também bombardeamentos da Força Aérea portuguesa e um ataque de guerrilheiros contra um posto militar. Segundo Conchiglia:

A confluência de guerrilheiros e de povo que assistiu à conferência do MPLA assim como um incidente entre guerrilheiros, que se traduziu na explosão duma granada, atraiu a atenção do exército português que atacou uma base de trânsito onde ainda se encontrava o médico e dirigente do MPLA, 
Américo Boavida. Este tinha ficado para trás do grosso dos combatentes do MPLA evacuados da região depois da conferencia, para tratar uns feridos. Nestas circunstâncias, Boavida foi morto durante um ataque dum helicóptero português.

(Mendonça 106)

O que mais impressionou Conchiglia foi "[...] a pobreza dos meios e a incrível vontade de avançar e travar a luta que demonstravam muitos dos combatentes [...] que passavam fome, como nós, mas que pareciam muito determinados" (Mendonça 107).

Conchiglia não se recorda do título dos filmes resultantes da primeira viagem a Angola. Um documentário, de 20 minutos, passou no programa de informação mais relevante em Itália, TV7, apresentado por Emilio Fede. ${ }^{10}$ Um outro filme de 80 minutos, com entrevistas a guerrilheiros, foi apresentado no Festival PanAfricano da Argélia em 1969 e uma cópia foi entregue ao Departamento de Informação do MPLA. Também em 1969, Conchiglia publicou ainda, em Roma e na Lerici, o livro Guerra di popolo in Angola (Guerra popular em Angola) documentado com fotos.

\section{Projeção cinematográfica do combate pela liberdade}

Como é que os movimentos de libertação usaram o cinema para propor a sua própria visão? Aparentemente, em Angola, apenas o MPLA teve recursos, humanos e financeiros, para usar o cinema como arma. A retaguarda exilada mobilizou simpatias sobretudo em França e em Itália. O MPLA apoia-se, portanto, também na criatividade de intelectuais de diversas origens que militam a favor da causa da independência.

Em 1970, Conchiglia e de Stefani, que, entretanto, tinham criado a Associazione per i Rapporti con i Movimenti Africani di Liberazione (Associação para as Relações com Movimentos Africanos de Liberação, ARMAL), regressam a Angola com uma equipa mais numerosa, e não em reportagem, mas para filmar a cores. Queriam fazer um filme inspirado em $A$

\footnotetext{
${ }^{10}$ A RAI desconhece o paradeiro desta reportagem. Apenas identificou a existência de outra, da autoria de Fede, sobre a FRELIMO.
} 
batalha de Argel (1966), de Gillo Pontecorvo (1919-2006), que procurou reconstituir a luta travada, entre 1954-1962, contra o colonialismo francês, na Argélia, mas que fixasse o quotidiano dos guerrilheiros e a mobilização do povo para lutar e participar na reconstrução nacional pós-independência.

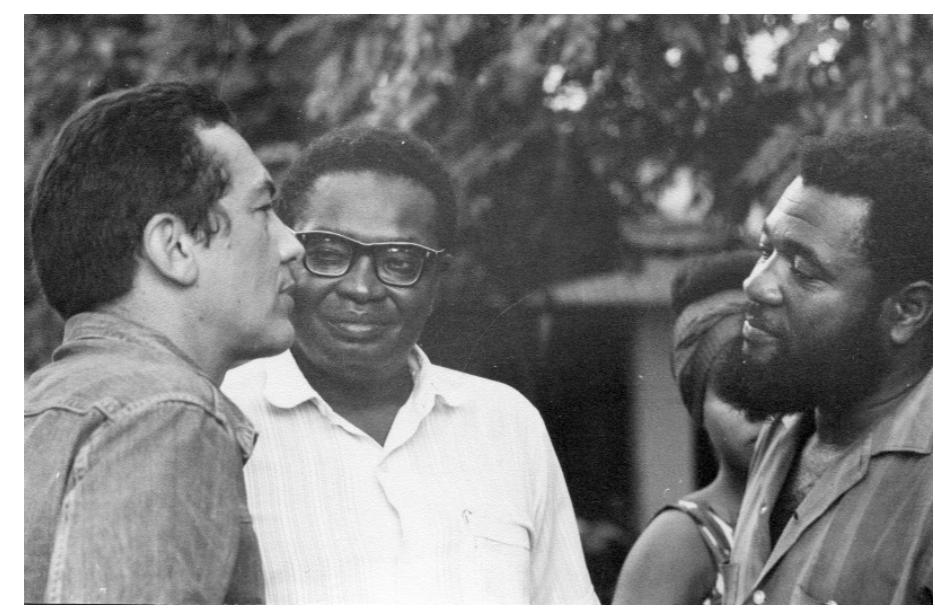

Fig. 2. Stefano di Stefani com Agostinho Neto. (c) Augusta Conchiglia

Segundo Conchiglia, o comandante Saidy Mingas foi escolhido como ator principal na filmagem da história "de um quadro (um citadino) enviado para mobilizar o povo contra o colonialismo" (Piçarra, "O cinema" 26). Porém, a chegada do tempo das chuvas e uma ofensiva militar portuguesa interromperam as filmagens. Durante o interregno, um desacordo sobre o que deveria ser o filme provocou uma rutura entre membros da equipa de rodagem. Dissidentes, Conchiglia e de Stefani realizaram uma longa-metragem relatando a história de um guerrilheiro do Leste, Borges. Os outros membros da equipa, Lionello Massobrio, Guelfo Guelfi e a norueguesa Randi Krokaa, readaptaram o argumento inicial dando a esta o papel de uma jornalista que visita as zonas libertadas do Leste de Angola e relata a vida dos guerrilheiros, sempre com o Comandante Mingas como figura chave. Desta incursão cinematográfica em Angola resultaram, portanto, dois filmes. 
La vittoria è certa (A vitória está certa), filme a cores da equipa "dissidente," foi realizado por Lionello Massobrio. ${ }^{11} \mathrm{O}$ genérico inicial informa que esta é uma produção da Luanda Cine de Roma e do Departamento de informação e propaganda do MPLA e que nele colaboraram militantes da terceira região político-militar do movimento e pioneiros do campo de Ngangula. Informa-se adicionalmente que o filme foi sonorizado em Lisboa com o apoio dos "companheiros da Casa de Angola." A sonorização, feita posteriormente e que perturba o efeito documental pretendido, resultou de um revés: "Os guerrilheiros que transportavam o material, na travessia de uma pontezinha de tronco de árvore, caíram ao rio com todo o equipamento de som, que se perdeu irreversivelmente" (Mendonça 108).

Devido à voz off italiano, e ao ter sido dobrado por angolanos residentes em Portugal, a banda sonora tem, no entender de Conchiglia, "momentos surrealistas" (Piçarra, "O cinema" 28). Isso é devido aos contrastes entre a expressão urbana de quem assegurou a dobragem e àquela que resultaria da realidade da guerra no mato.

A narração deste documentário ficcional é feita pela protagonista. Interpretando uma jornalista que entra clandestinamente em Angola para reportar a luta, alerta que o filme não tem ambição histórica. A obra reconstitui as dificuldades vividas no terreno com a entrada no país, a necessidade de os clandestinos permanecerem escondidos durante o patrulhamento da Força Aérea portuguesa e a longa caminhada até a um acampamento numa zona libertada onde a jornalista e uma militante do MPLA que a assiste na reportagem são apresentadas ao comandante e aos guerrilheiros. É explicado às repórteres que aquele é um campo de treinos e que, nesta área, os portugueses estão acuados nas suas casernas, onde são atacados pelos guerrilheiros. Acrescenta-se ainda que a luta do MPLA não é solitária e que, no mundo, estão em curso outras lutas assim. É tempo da destruição do imperialismo e os povos que fazem a luta são povos amigos - é este o enquadramento ideológico dado.

La vittoria è certa esforça-se por mostrar como os civis — crianças, mulheres e velhos-vivem perto da base militar. Procura-se evidenciar que, apesar das dificuldades, há alegria e camaradagem. Entre o registo (reconstituição ou documentação de ações reais?) de operações, como a destruição de uma ponte e

\footnotetext{
${ }^{11}$ Agradeço à embaixada angolana em Itália a cedência de cópia do filme.
} 
um momento de autocrítica por um dos operacionais devido à má utilização do cordão detonador, documenta-se a resolução de questões logísticas e como procura solucionar-se a escassez de alimentos.

O outro filme, documental e a preto e branco, foi feito pela dupla Conchiglia e de Stefani. Trata-se de A proposito dell'Angola (A propósito de Angola), estreado em Itália a 1 de abril de $1973 .{ }^{12}$ A figura do protagonista, interpretada por Borges, é a de um combatente oriundo de Cabinda. O filme regista a sua vida no acampamento, a instrução com novos armamentos e a rotina no centro de instrução. Termina com uma emboscada a uma coluna motorizada portuguesa. A questão da dificuldade em arranjar comida está muito presente. Luigi Pistilli, ator italiano reconhecido pelas suas representações de Brecht, emprestou a voz à narração do filme o que, segundo Conchiglia, dá grande verosimilhança a tudo o que é dito. ${ }^{13}$

\section{Militância e prisão colonial - Vieira por Maldoror}

Sarah Maldoror (1939-) é de Condom, na França, filha de mãe francesa e de pai natural da Ilha de Maria Galante, nas Antilhas Francesas. ${ }^{14}$ Cineasta "engajada" nas lutas de libertação dos povos africanos, a dimensão poética do seu cinema, político, fá-lo extravasar a categorização como militante. Para isso muito contribuíram as adaptações cinematográficas de obras de Luandino Vieira.

Tal como Ousmane Sembène, Souleymane Cissé, Abderrahmane Sissako e Idrissa Ouédraogo, e com uma bolsa de cinema dada pela URSS, Sarah Maldoror estudou, entre 1961 e 1962, no Instituto Nacional de Cinematografia da União Soviética, em Moscovo, onde teve como professores Serguei Guerassimov (1906-85) e Mark Donskoi (1901-81).

Porque é que os africanos, ou europeus com raízes africanas, foram para a URSS estudar cinema? Está documentado como a URSS deu apoio militar a muitos movimentos de libertação africanos, muitas vezes via Cuba. O que está

\footnotetext{
${ }^{12}$ A produção do filme está atribuída à IDI Cinematografica, sediada em Roma e fundada por Gian Vittorio Baldi (1930-2015) em 1962 e encerrado em 1973 (Bertozzi 169).

${ }^{13}$ Não obstante o depósito na Cinecitta Luce, não é possível visionar a cópia existente. Os direitos de distribuição foram sublicenciados à Myra, que não tem, de momento, digitalização disponível do mesmo.

${ }^{14}$ Maldoror nasceu com o apelido "Barbados," mas adotou o seu nome artístico em homenagem a Isidore Ducasse (1846-1870), autor d'Os cantos de Maldoror (1869).
} 
por analisar aprofundadamente é como é que essa "amizade" se traduziu em afinidades entre o "cinema soviético" e o cinema feito em África, a partir da frequência, por realizadores africanos, de escolas de cinema russas.

Durante a década de 60 a URSS convidou, concedendo bolsas de estudo, vários africanos ou europeus de origem africana, para irem estudar cinema nas suas escolas. Equipamento de filmagem e unidades cinematográficas móveis foram também oferecidos aos países socialistas africanos, para apoiar o surgimento das suas cinematografias. Muitos dos estudantes provieram da África francófona, uma vez que a França não acolhia os estudantes de origem africana que queriam estudar cinema. Para estes a opção era então a URSS, onde o cinema era assumido politicamente como modo de promover o socialismo. No entanto, a Rússia Soviética também pretendia promover uma estética cinematográfica que servisse o internacionalismo socialista desejado.

Como propõe Basia Lewandowska Cummings: "Whether for diplomacy, advocacy, as a form of soft power or as a means of propaganda, cinema was a tool through which the Soviet Union wanted to extend itself; through images it saw its own expansion into Africa." Cummings defende ainda que: "what emerges from an investigation into African filmmaking and its relationship with the Soviet Union - particularly in West Africa during the 1960s-1990s, and cinema cultures in Lusophone countries in the 1970s - is a cinegeography of socialist friendship." Por outro lado, a guerra da Argélia, que estimulou, em África, o surgimento de filmes militantes, feitos para promover a independência do país ou a solidariedade com a causa, também acabou por influenciar a futura realizadora. As imagens da repressão e o uso de tortura pelo exército francês assim como dos guerrilheiros, entre outras - relativas à questão dos refugiados e dos órfãos de guerra, por exemplo - fizeram parte das representações surgidas nesses filmes militantes que foram usadas como referência por Maldoror.

Foi, pois, com grande proximidade, e através da influência de Mário Pinto de Andrade (1928-1990), de quem Maldoror foi companheira, que acompanhou os primórdios do MPLA — de que o poeta foi um dos fundadores em 1952 e que presidiu entre 1960-1962 — durante o início da luta armada em Angola. Após uma passagem por Marrocos, estabeleceu-se em Argel onde foi assistente de realização de Gillo Pontecorvo em A batalha de Argel (1966), que veio a influenciar o cinema político subsequente e os filmes de Maldoror. 
Pouco tempo depois iniciou-se na realização-foi a primeira cineasta a representar, na ficção, as lutas pela independência na África Lusófona—com a curta-metragem Monangambé (1968). De A batalha de Argel trouxe o único ator profissional, o argelino Mohamed Zinnet (1931-1995). O filme foi filmado em três semanas, próximo de Argel, com atores não profissionais e é a adaptação, por Maldoror, Pinto de Andrade e Serge Michel, de O fato completo de Lucas Matesso (1967), de Luandino Vieira. Quanto ao filme, teve apoio financeirosete mil dólares americanos - e técnico do Departamento de Orientação e Informação da Frente de Libertação Nacional e do Exército Nacional Popular. O genérico final é uma sequência montada de fotografias de guerrilheiros, de Augusta Conchiglia. ${ }^{15}$

Monangambé representa o desconhecimento da cultura angolana pelos portugueses e o tratamento brutal a que os prisioneiros políticos eram sujeitos. Após uma sequência inicial em que vários negros são transportados até uma prisão, mostra-se a visita de uma mulher (Elisa Pestana) ao companheiro, detido. Enquanto se tocam e abraçam, a mulher sussurra-lhe algo que faz com que o guarda (Zinnet) os afaste e leve Matesso. Através do conto, sabe-se que não há provas contra Matesso, e é o sussurro da mulher dizendo que trouxe o "fato completo que é tido como indício suspeitoso. ${ }^{16} \mathrm{Na}$ sala do diretor, dominada por um enorme retrato de Salazar, o guarda relata a situação: fala-se, com suspeita, do tal "fato completo" mencionado, que manda revistar os objetos trazidos. Apenas roupa e uma panela com comida. A frustração crescente do guarda é dirigida depois para o prisioneiro. Maldoror mostra-o na solitária, num diálogo íntimo, através do qual este revela que, após dias de jejum forçado, procuraram que falasse através da oferta de comida. Posteriormente, Matesso é interrogado, sob o olhar sem vida do retrato de Salazar. É submetido à tortura, mantido imobilizado, como uma estátua, e, finalmente, quebra fisicamente.

Durante todo o filme, e exceto quando se escutam escassos diálogos em francês, ouve-se o jazz avant-garde do Art Ensemble de Chicago (que a autora conheceu em Paris, a tocar na rua) totalmente improvisado sobre as imagens do

\footnotetext{
${ }^{15}$ Segundo Conchiglia, vieram a conhecer-se em Argel, por intermédio da montadora Jacqueline Meppiel (1928-2011), durante o Festival Pan-Africano, em 1969 ("Re: Filmes sobre").

${ }^{16}$ Como se explica previamente, o "fato completo" era um prato de feijão com peixe, tudo cozinhado em óleo de palma, e acompanhado com banana, comido e assim designado nos musseques de Luanda.
} 
filme já após a montagem. O resultado é dilacerante, potenciando a perturbação e uma sensação de claustrofobia e desespero.

Da obra de Luandino é retido o diálogo íntimo, do sujeito angolano silenciado, cuja história é contada numa perspetiva alternativa e contestatária do colonizador opressor. Maldoror traduz em imagens cinematográficos o diálogo entre a militância e a arte "imaginando" através das palavras de Luandino e usando o jazz como grito libertário. O fato completo de Lucas Matesso faz parte do conjunto publicado com o título Vidas novas, e terá sido escrito de 28 de junho a 28 de julho de 1962 no Pavilhão Prisional da PIDE em Luanda. Após ampla circulação em fotocópias, foi editado pela primeira vez em 1968, em Paris, pelas Edições Anti-Colonial, e posteriormente, em 1971, em conjunto com A vida verdadeira de Domingos Xavier, pela Présence africaine.$^{17}$ A aproximação do texto do conto - e a sua adaptação cinematográfica — ao diário de Vieira, agora publicado em Papéis da prisão, denota as reverberações existentes:

Continuam as torturas tendo estado a espancar um moço das 3 menos 10 até às 4 horas. Nem sei como almocei. Era berros horríveis e mesmo assim parecia que lhe tinha posto um lenço na boca, porque chegavam abafados. Estive quase a vomitar o almoço, o estômago recusa-se a digerir e cada vez me sinto pior. Terei ainda que aguentar isto muito tempo? Ficarei a mesma pessoa? Às vezes tenho medo de perder a cabeça, de enlouquecer. (Vieira 18-19)

Em 1971, ano em que o cinema engagé dominou a programação do Festival de Cannes, Monangambé foi selecionado para a secção paralela, não competitiva, da Quinzena dos Realizadores, em representação de Angola que, ainda antes de ser independente, via, assim, reconhecida a luta para sê-lo pela comunidade cinematográfica. ${ }^{18}$

\footnotetext{
${ }^{17}$ Só foi publicado em Portugal em 1976.

${ }^{18}$ Recebeu ainda um prémio no Dinar Film Festival, em França, o International Critics' Prize no Carthage Film Festival, na Tunísia, e foi selecionado para o terceiro Festival Panafricain de Ougadougou (FESPACO) em 1972.
} 
Na sequência da publicação em França, em 1971, de A vida verdadeira de Domingos Xavier (edição conjunta com $O$ fato completo de Lucas Matesso) Sambizanga (1972) foi rodado durante sete semanas em Brazzaville, no Congo, e foi montado, ao longo de dez semanas, em Paris. Em entrevista a Raquel Schefer, Maldoror explica:

Filmei no Congo-Brazzaville porque não era possível fazê-lo em Angola. O Congo Brazzaville era independente e, além disso, interessava-me a arquitectura da prisão de Brazzaville. $\mathrm{O}$ rio Congo também era impressionante. Quando faço um filme, os décors são tão importantes quanto o texto. [...] Quando vi o rio Congo, soube imediatamente que era ali que iria filmar. Cinematograficamente, tanto a prisão, quanto o rio me pareciam excepcionais. (149)

Enquadrado pela militância no MPLA mas com uma sensibilidade visual inegável, Sambizanga procura mostrar a vida real do povo angolano e os laços de solidariedade existentes. A equipa técnica era predominantemente francesa (incluindo o diretor de fotografia Claude Agostini), e os atores não profissionais foram recrutados sobretudo entre militantes do MPLA e do PAIGC. A economista Elisa Andrade, radicada em Argel, repetiu a colaboração com Maldoror e interpretou o papel principal, como Maria. Através do ponto de vista desta, Maldoror mostra a importância da participação das mulheres na luta pela independência - também nos Papéis da prisão de Vieira, esta importância fica também documentada de modo profundo e emocionante.

Tanit d'Or do Festival de Cinema de Cartago e International Catholic Film Office Award no FESPACO em 1973, é a adaptação de A vida verdadeira de Domingos Xavier (1961), tendo o argumento sido assinado também por Pinto de Andrade e pelo escritor e jornalista Maurice Pons. Aprofunda os temas já abordados em Monagambé, e opta por adaptar para cinema alguns acontecimentos que provocaram, em 1961, o despertar da consciência anticolonial. Daí decorre um registo mais intimista — o mais conseguido no filme a par da fotografia. Não ter feito uma obra especificamente sobre a luta armada valeu críticas à realizadora. Esta, porém, esclarece que Sambizanga não é um filme de guerra: 
O filme pretende filmar uma história real que ocorreu nos anos 60 no início da resistência anti-colonial em Angola. Mostro como as pessoas tentam organizar um movimento de resistência. As pessoas culparam-me $[\ldots]$ por ter escolhido actores que, disseram, são demasiados belos. Bem, são de facto pessoas negras que são belas e é tudo. [...] Em termos de ritmo do filme, tentei recriar o ritmo lento que caracteriza a vida africana. Nada é inventado. Tudo o que mostro no filme deriva da minha própria percepção dessa realidade. (71)

Sambizanga é o nome de um bairro de operários em Luanda, no qual se localizava uma prisão do regime colonial português cujo assalto, em 1961, constituiu o

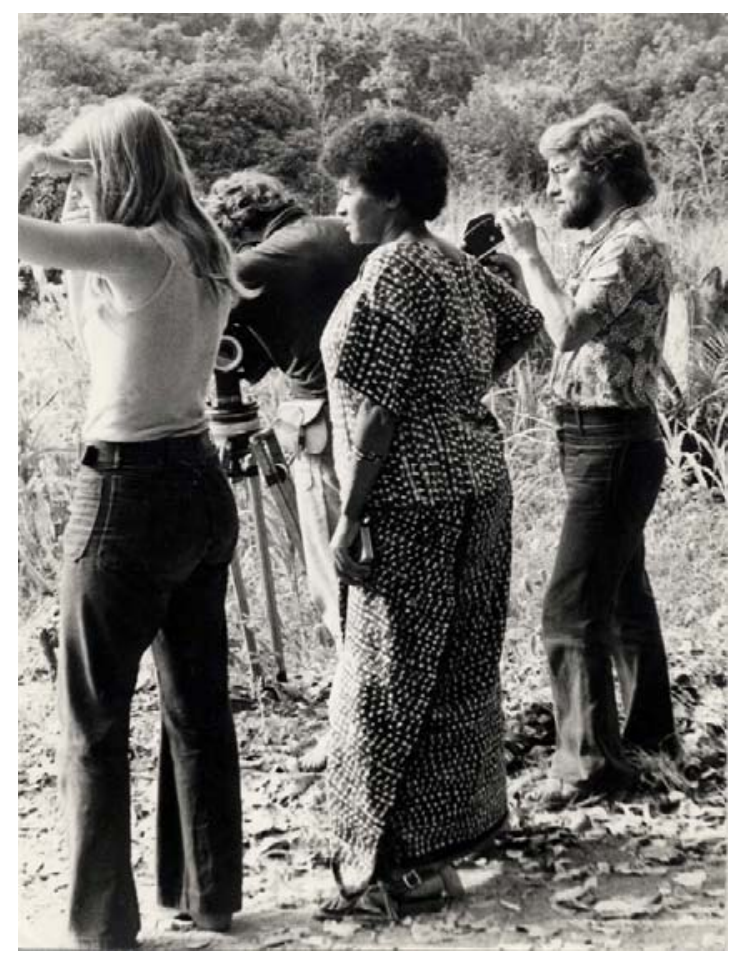

Fig. 3. Sarah Maldoror na rodagem de Sambizanga (1972). (C) Sarah Maldoror 
primeiro ato coordenado de sublevação armada contra o regime português. $\mathrm{O}$ filme pretende mostrar a participação das mulheres na luta pela libertação através do ponto de vista de Maria. Esta viaja do interior até Luanda à procura do marido, Domingos, um trabalhador exemplar preso por razões políticas e torturado até à morte. A longa-metragem pretende mostrar a crueldade da polícia política portuguesa e o sadismo dos seus elementos: "Fui muito criticada pelas cenas de tortura, por ter feito os actores emagrecer. As agressões e os golpes, na sua dimensão física, de contacto entre os corpos, têm muito mais efeito do que uma cena de chicotearia. Aquilo que me interessava era o sofrimento que cada novo soco representava" (Schefer 145).

A vida verdadeira de Domingos Xavier foi escrito ainda antes da segunda prisão de Luandino Vieira, em 1961, e teve a sua primeira circulação em fotocópias distribuídas pelos membros da Sociedade Cultural de Angola.

O seu projecto literário e político já estava em marcha antes da prisão, em situação de clandestinidade, como é visível também em "A Vida Verdadeira de Domingos Xavier," escrito, nas palavras de Luandino Vieira, em 'liberdade vigiada', ou seja, em clandestinidade e já com a ideia de que nunca poderia ser publicado e de que deveria ser enviado para fora, como foi, para que, mais tarde, Mário Pinto de Andrade traduzisse a obra para a Présence Africaine. (Vieira 16)

Não há, no filme, qualquer referência positiva aos colonos portugueses nem ao desenvolvimento eventual do território, habitual nas obras de propaganda do Estado Novo, projetadas não só em Portugal e "províncias ultramarinas," mas também internacionalmente.

A sequência familiar do início do filme, uma representação belíssima do amor familiar, com a refeição e o repouso que se lhe segue, mas também de uma grande fisicalidade, é o coração do filme. Se sublinha a paz familiar é para depois contrastar, a negro, com o processo de prisão, sem culpa formada, de Domingos e a tortura a que este sucumbe enquanto Maria sofre a tortura do desespero, durante a sua busca pelo marido, antes de conhecer a dor da sua perda definitiva.

O registo intimista de Sambizanga e a opção de não ter feito uma obra especificamente sobre a luta armada valeram algumas críticas à realizadora. 
Porém, segundo a autora, se Sambizanga pretendia tornar o mundo consciente da luta que se travava em Angola, não era um "filme de retórica política." A brutalidade do regime colonial português e as dificuldades da organização, clandestina, da luta pela independência estão em foco, mas o no filme está em primeiro plano é o movimento de busca — e a consciencialização política—de Maria. Maria que, com um filho nos braços, parte em busca de Domingos e que chega a Luanda quando este já sucumbiu à tortura faz um movimento do interior da casa, onde é mãe e mulher, para o coração da luta. É uma mulher bela, forte, com a dignidade de que é investida pela maternidade e pelo companheirismo, mas, sobretudo, pela coragem de sair da casa, onde o lume se apagou após a família ter sido destroçada, e mergulhar no coração das trevas, numa busca que a leva à prisão, e a faz emergir, primeiro inconformada com o silêncio e depois consagrada ao desafio.

Como propõe Marissa Moorman, em Sambizanga, "blacks and whites and men and women refigure their relationships and roles in the context of the struggle against the colonizer" (111). A identidade de Maria, no centro do filme de Maldoror (não era central, no conto de Luandino), vai-se recriando em relações constitutivas quando, na sua busca, conta com a solidariedade de outras mulheres e homens que a ajudam no percurso. Reconhecendo, não obstante o lado engajado do filme, que termina numa cena festiva de apoiantes do MPLA, Moorman sublinha o processo de (re-)identificação de Maria: da casa para o mundo, da família para a comunidade, da mãe-esposa para a mulher de luta. Frank Ukadike admite que Sambizanga dá especial atenção à subjetividade feminina ("Reclaiming Images"). Aquilo com que Moorman discorda de Ukadike (uma crítica que partilho) está inscrito em Black African Cinema:

The film is structured with a deliberate feminist slant aimed at giving credibility to women's active participation and involvement in this dangerous liberation struggle. This emphasis, lengthily dealt with, dilutes the impact of the film's concern with armed guerrilla struggle. Thus, regarding its effectiveness, some critics thought that this deficiency amounted to romanticizing what could have constituted a forceful delineation of a liberationist uprising. However, 
Sambizanga ultimately ratifies, with an indelible stamp, African revolutionary agitation. (234)

A perceção do filme como sendo relativo à luta armada é questionável. Não o é, de facto. O que, de algum modo, a visão de Ukadike dá é eco aos lamentos daqueles que criticaram Maldoror por não ter feito um filme mais especificamente sobre a luta pela independência em vez de ter dado tanta atenção à mulher de Domingos, Maria, ao ponto de fazer dela mais importante do que o herói vítima direta da tortura. Se Ukadike considera que tanto Domingos como Maria são símbolos de "coragem desafiadora," Moorman critica a sua leitura segundo a qual apenas Domingos pode simbolizar a angolanidade (117). Esta propõe que a leitura de Ukadike figura o tema da nação como masculino relegando as especificidades sobre o estatuto e atividades das mulheres e suas atividades à categoria de distração dos "assuntos sérios" (117).

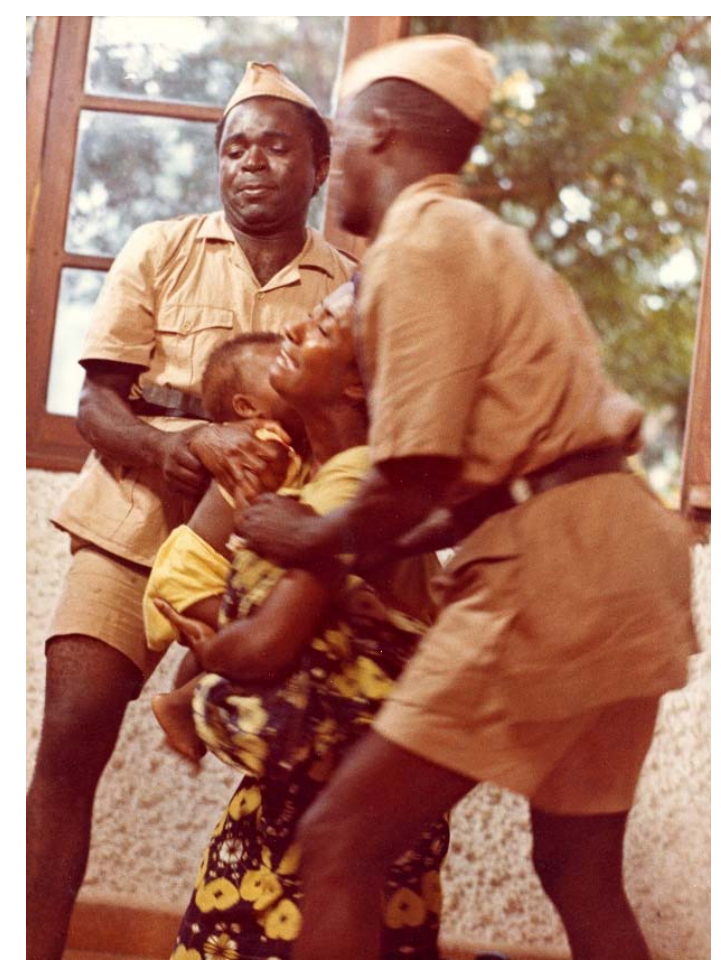

Fig. 4. Cena da expulsão de Maria, em Sambizanga (1972). (C) Sarah Maldoror 
À asserção de que o foco de Sambizanga é uma "deficiência" da obra e uma "romantização" subjaz a ideia que as mulheres não podem uma vez mais ser figuras centrais nas nações e nas lutas de libertação. Ao caracterizar como romantização a intriga à volta de Maria questiona a centralidade da participação da mulher nas lutas pelas independências obscurecendo o papel efetivo que estas tiveram, conotando os movimentos de libertação com um género, masculino.

Não obstante as necessárias adaptações da história para potenciar a perspetiva feminina, Maldoror assume a fidelidade ao romance de Vieira quanto à trama, nomeadamente no que respeitou à cor da pele. Tal não foi uma questão menor. Após a independência de Angola, quando Sambizanga foi projetado no país, tal opção gerou algumas críticas, assim como, após as sessões de cinema, alguma fúria popular dirigida a mestiços. Como explica Maldoror: "I was faithful to the novel. When [Vieira] had a white engineer who helped the blacks, or a mulatto who was a torturer, I respected the story. Naturally in making a film you have a political option. I make a film according to my political ideas. I made the choice when I picked the novel to film" (Pfaff 14).

Sambizanga foi pioneiro e distinguiu-se por ter prenunciado a criação de uma produção de cinema especificamente africana; por ser uma obra ficcional inspirada pelos movimentos de libertação africanos - no caso, específico, pelo angolano, e pela opção em assumir um ponto de vista feminino. ${ }^{19}$ Visualmente bem conseguido, com grandes planos notáveis, bem montado, é fragilizado por um certo didatismo político embora a opção de Maldoror de filmar num registo íntimo o distinga de um cinema militante de vocação coletivista, dominante no período em que foi realizado.

\section{Conclusão}

Se alguns dos intelectuais ligados aos movimentos de libertação se tornaram cinéfilos no contexto cineclubista fomentado em Angola na década de 50, é um facto que não houve formação de técnicos contributiva para suprir a necessidade de realizadores quando o cinema foi posto ao serviço da luta pela independência. Só após a independência é que cineclubistas de sempre, como Francisco Castro

${ }^{19}$ Sambizanga só pode ser exibido em Angola após o 25 de Abril de 1974 e há vários testemunhos relativos à sua exibição em cineclubes locais. 
Rodrigues (1920-2015), fundador do Cineclube do Lobito, puderam reclamar a militância através do cinema.

Já o impacto, na luta pela independência em curso, das reportagens filmadas por repórteres internacionais que entraram clandestinamente em Angola não pode ser subestimado. Além de terem posto o colonialismo português sob maior escrutínio das instâncias de decisão política internacionais, expuseram, perante a opinião pública, as democracias ocidentais que apoiavam, nas Nações Unidas, as posições portuguesas, nomeadamente a insistência de que Portugal, era de Minho a Timor, uma nação multirracial, pluricontinental, sem colónias e sim com províncias ultramarinas. Sobretudo, acabaram mobilizar os repórteres que passaram pelo território. Dorkins, o operador de câmara de Angola: Journey to a War, terá voltado, em 1963, a Angola para ajudar na luta pela independência. Conchiglia e de Stefani, após a realização, em 1968, da primeira reportagem televisiva, e de um filme, ambos relativos à ação do MPLA, criam a ARMAL, para apoiar os movimentos de libertação em África. Em 1969, Conchiglia publica, em Itália, um livro, com as suas fotos, sobre a luta pela independência travada em Angola. Em 1970, a dupla regressa, clandestinamente, já numa perspetiva de cinema militante e com uma equipa alargada, para fazer filmes que fixem o quotidiano dos guerrilheiros e das populações nas zonas libertadas. A equipa entra em rutura mas, pela primeira vez, o MPLA dispõe de recursos para apoiar um filme militante, La vittoria è certa. A perda da banda sonora original inviabilizou, no entanto, que o filme cumprisse, ainda antes de 11 de novembro de 1975 , a projeção cinematográfica da luta que se travava.

Em termos cinematográficos, foram quase exclusivamente os filmes de Maldoror a projetar Angola como nação-note-se como Monangambé representou Angola, em 1971, na secção paralela Quinzena dos Realizadores, no Festival de Cannes que assim reconhecia, através da comunidade cinéfila, este território como nação ainda antes da independência do mesmo, em 1975.

É à luz da influência estética, mas também política, do cinema soviético, e de alguns temas propostos pelos filmes militantes feitos sobre a Argélia que, proponho, sejam olhados os filmes "angolanos" de Maldoror-aqueles que mais fizeram internacionalmente pela causa do MPLA.

Se o VGIK determinou a formação cinematográfica de Maldoror, a experiência de vida na Argélia e influência do cinema militante feito sobre a luta desse país pela independência, mas também a integração no internacionalismo 
cinematográfico (expresso na realização de obras coletivas como Loin du Vietnam (Longe do Vietname, 1967) ou Festival pan-africano d'Argel (Festival panafricano de Argel, 1969), que, como Monangambé, inclui fotografias de Conchiglia) marcaram fortemente os filmes "angolanos" da realizadora. O tema da tortura e da violência colonial assim como a representação do lutador pela liberdade - no caso angolano, homens do povo, sem formação militar, mas que militam politicamente ao serviço da causa da libertação - são comuns a Monangambé e Sambizanga, inspirados em contos de Luandino Vieira, ele próprio preso e vítima, de longa data, da violência do sistema de encarceramento colonial português.

Recupero as palavras de Francisco Castro Rodrigues, que promoveu o uso do cinema como uma arma para a libertação de Angola. Publicadas no primeiro número do Boletim Informativo do Cine Clube do Lobito em agosto de 1974, anteriores à independência de Angola ainda, defendem a criação de um projeto para o cinema angolano assente na militância:

Há muitos anos, num dos primeiros números da revista francesa Estados Gerais do Cinema, foi publicado um "manifesto anticapitalista e anti-imperialista" para a promoção de um cinema militante. [...] Ao novo produto, pois desta sociedade ainda de consumo, o filme, ninguém mais que o amador, sem dependências comerciais nem obediências a grupos de pressão, poderá melhor usá-lo como nova arma ao serviço da cultura, instrumento de paz e de descolonização, de compreensão entre os povos, produto novo ao serviço da cultura, instrumento da paz e de descolonização, de compreensão entre os povos. (Rodrigues e Dionísio 266)

Quando se tornou diretor da Televisão Popular de Angola e dirigiu o Instituto Angolano de Cinema, Luandino Vieira procurou concretizar um projeto com estas características. A guerra civil e a falta de recursos, entre outros motivos, obstaram, porém, à sua realização. E embora o cinema angolano tenha um "futuro sempre adiado," nas palavras de José Mena Abrantes, o certo é que em Angola a militância cinematográfica e os projetos de autor têm mantido viva a atividade cinematográfica no país. 


\section{Obras Citadas}

Abrantes, José Mena. "Cinema angolano: um passado com o presente sempre adiado." Angola, o nascimento de uma nação, vol. 3: o cinema da independência, editado por Maria do Carmo Piçarra e Jorge António, Guerra \& Paz, 2015, pp. 15-46.

Andrade-Watkins, Claire. "Portuguese African Cinema: Historical and Contemporary Perspectives: 1969 to 1993." African Cinema, vol. 26, no. 3, 1995, pp. 134-50.

Bertozzi, Marco. Storia del documentario italiano: immagini e culture dell'altro cinema. Marsilio, 2008.

Cumming, Basia Lewandowska. "Soviet Cinema and African Filmmaking." Africa is a Country, 20 abr. 2012, africasacountry.com/2012/04/sovietcinema-and-african-filmmaking.

Cunha, Paulo. "A alvorada do cineclubismo." Angola, o nascimento de uma nação, vol. 2: o cinema da libertação, editado por Maria do Carmo Piçarra e Jorge António, Guerra \& Paz, 2014, pp. 43-64.

Cunha, Paulo e Catarina Laranjeiro. "Guiné-Bissau: do cinema do estado ao cinema fora do estado." Rebeca, vol. 5, no. 2, 2016, pp. 1-23.

Conchiglia, Augusta. "Re: Filmes sobre Angola antes da independência." Recebido por Maria do Carmo Piçarra, 6 de set. 2012.

-. Guerra di popolo in Angola: reportage fotografico realizzato con i partigiani del MPLA. Lerici, 1969.

Faria, António. Introdução ao cinema angolano. Autor, 1965.

Faria, Manuel. "Introdução a um futuro do cinema angolano." Diálogo, vol. 3, 1964, pp. 13-15.

Gray, Ros. "Linhas claras num mapa internacionalista." Angola, o nascimento de uma nação, vol. 3: o cinema da independência, editado por Maria do Carmo Piçarra e Jorge António, Guerra \& Paz, 2015, pp. 47-74.

-. "Cinema on the Cultural Front: Filmmaking and the Mozambican Revolution.” Journal of African Cinemas vol. 3, no. 2, 2012, pp. 139-60.

Henebelle, Monique. "Sambizanga: un film de Sarah Maldoror sur les débuts de la guerre de libération en Angola." L'Afrique Littéraire et Artistique, no. 28, 1973, pp. 78-87. 
Maldoror, Sarah. "Entretien avec Sarah Maldoror.” Ecran, vol. 73, no. 15, 1973, pp. 70-71.

—. "Sarah Maldoror." L’Afrique Littéraire et Artistique, no. 49, 1978, pp. 8891.

Mendonça, José Luís. "Augusta Conchiglia: repórter da guerrilha angolana." Austral: Revista de Bordo (TAAG), março/abril 2012, pp. 99-108.

Moorman, Marissa. "Of Westerns, Women, and War: Re-Situating Angolan Cinema and the Nation." Research in African Literatures, vol. 32, no. 3, 2001, pp. 103-22.

Mulvey, Laura. "Visual Pleasure and Narrative Cinema." Screen, vol. 16, no. 3, 1975, pp. 6-18.

Pangom, Gérard, and Gérard Camy. Un cinéma engagé. Art/Mille et Une Nuits, 1997.

Piçarra, Maria do Carmo. "Cinema império: o "fado tropical' na propaganda." Angola, o nascimento de uma nação, vol. 1: o cinema do império, editado por Maria do Carmo Piçarra e Jorge António, Guerra \& Paz, 2013, pp. 1552.

—. "O cinema é uma arma." Angola, o nascimento de uma nação, vol. 2: o cinema da libertação, editado por Maria do Carmo Piçarra e Jorge António, Guerra \& Paz, 2014, pp. 15-42.

-, e Teresa Castro. "Colonial reflections, Post-colonial Refractions: Film and the Moving Image in the Portuguese (Post-)Colonial Situation." Re(imagining) African Independence: Film, Visual Arts and the Fall of the Portuguese Empire, editado por Maria do Carmo Piçarra e Teresa Castro, Peter Lang, 2017, pp. 111-30.

Pfaff, Françoise. "Sarah Maldoror." Twenty-five Black African Filmmakers. Greenwood, 1988.

Ramos, Afonso. "Rarely Penetrated by Camera or Film: NBC's Angola: Journey to a War (1961)." Re(imagining) African Independence: Film, Visual Arts and the Fall of the Portuguese Empire, editado por Maria do Carmo Piçarra e Teresa Castro, Peter Lang, 2017, pp. 111-30.

Ribeiro, Margarida Calafate, e Roberto Vecchi. "Papéis críticos avulsos." Papéis da prisão. apontamentos, diário, correspondência (1962-1971), por José Luandino Vieira, editado por Margarida Calafate Ribeiro, Mónica V. Silva e Roberto Vecchi, Caminho, 2015, pp. 13-31. 
Rodrigues, Francisco Castro, e Eduarda Dionísio. Um cesto de cerejas: conversas, memórias, uma vida. Casa da Achada/Centro Mário Dionísio, 2009.

Rossi, Pierre-Pascal. Pour une guerre oubliée: avec les guerilleros de l'Angola. Julliard, 1969.

Serizahia, Jadot. "Il faut prendre d'assaut la télévision/ We Have to Take Television by Storm," Ecrans de Afrique, no. 12, 1995, pp. 6-11.

Schefer, Raquel. "Sarah Maldoror: o cinema da noite grávida de punhais." Angola, o nascimento de uma nação, vol. 3: o cinema da independência, editado por Maria do Carmo Piçarra e Jorge António, Guerra \& Paz, 2015, pp. 139-52.

Silva, Artur M.S. “Cinema experimental angolano.” Diálogo, no. 3, 1964, p. 13.

Vieira, José Luandino. Papéis da prisão. apontamentos, diário, correspondência (1962-1971), editado por Margarida Calafate Ribeiro, Mónica V. Silva e Roberto Vecchi, Caminho, 2015.

Ukadike, Nwachukwu Frank. Black African Cinema. U of California P, 1994.

-. "Reclaiming Images of Women in Films from Africa and the Black Diaspora." African Experiences of Cinema, editado por Imruh Baraki e Mbaye Cham. British Film Institute, 1996, pp. 194-208. 